\title{
Tonsillar cytokine expression between patients with tonsillar hypertrophy and recurrent tonsillitis
}

\author{
Emilia Mikola ${ }^{1}$, Varpu Elenius ${ }^{2 \dagger}$, Maria Saarinen ${ }^{2 \dagger}$, Oscar Palomares ${ }^{3,4,5}$, Matti Waris ${ }^{6,7}$, Riitta Turunen ${ }^{2}$, \\ Tuomo Puhakka1,8, Lotta Ivaska' ${ }^{1}$, Beate Rückert ${ }^{3,4}$, Alar Aab ${ }^{3,4}$, Tero Vahlberg' ${ }^{9}$, Tytti Vuorinen 6,7, \\ Tobias Allander ${ }^{10}$, Carlos A. Camargo Jr ${ }^{11,12}$, Mübeccel Akdis ${ }^{3,4}$, Cezmi A. Akdis ${ }^{3,4}$ and Tuomas Jartti $2^{*^{*}}$ (D)
}

\begin{abstract}
Background: Tonsils provide an innovative in vivo model for investigating immune response to infections and allergens. However, data are scarce on the differences in tonsillar virus infections and immune responses between patients with tonsillar hypertrophy or recurrent tonsillitis. We investigated the differences in virus detection and $T$ cell and interferon gene expression in patients undergoing tonsillectomy due to tonsillar hypertrophy or recurrent tonsillitis.

Methods: Tonsils of 89 surgical patients with tonsillar hypertrophy $(n=47)$ or recurrent tonsillitis $(n=42)$ were analysed. Patients were carefully characterized clinically. Standard questionnaire was used to asses preceding and allergy symptoms. Respiratory viruses were analysed in tonsils and nasopharynx by PCR. Quantitative real-time PCR was used to analyse intratonsillar gene expressions of IFN- $\alpha$, IFN- $\beta$, IFN- $\gamma$, IL-10, IL-13, IL-17, IL-28, IL-29, IL-37, TGF- $\beta$, FOXP3, GATA3, RORC2 and Tbet.

Results: Median age of the subjects was 15 years (range 2-60). Patients with tonsillar hypertrophy were younger, smoked less often, had less pollen allergy and had more adenovirus, bocavirus-1, coronavirus and rhinovirus in nasopharynx (all $P<0.05$ ). Only bocavirus-1 was more often detected in hypertrophic tonsils $(P<0.05)$. In age-adjusted analysis, tonsillar hypertrophy was associated with higher mRNA expressions of IL-37 $(P<0.05)$.

Conclusions: Intratonsillar T cell and interferon gene expressions appeared to be relatively stable for both tonsillar hypertrophy and recurrent tonsillitis. Of the studied cytokines, only newly discovered anti-inflammatory cytokine IL-37, was independently associated with tonsillar hypertrophy showing slightly stronger anti-inflammatory response in these patients.
\end{abstract}

Keywords: Allergy, Asthma, Child, Cytokine, Interferon, Interleukin, T helper cell, Tonsil, Virus

\section{Background}

Tonsillar disease is one of the most common disorders in the field of otorhinolaryngology. Different types of tonsillar disease include recurrent tonsillitis and tonsillar hypertrophy, with both leading to symptoms of mouth

\footnotetext{
*Correspondence: tuomas.jartti@utu.fi

${ }^{\dagger}$ Varpu Elenius and Maria Saarinen contributed equally as second author ${ }^{2}$ Department of Paediatrics and Adolescent Medicine, Turku University Hospital and Turku University, P.O. Box 52, 20520 Turku, Finland

Full list of author information is available at the end of the article
}

breathing, snoring, dyspnea, apnea or dysphagia. Treatment is usually antibiotics or tonsillectomy.

Tonsils are secondary lymphoid organs, which are centrally located at the beginning of the respiratory and gastrointestinal tracts where the immune system first comes into contact with infections agents and allergens [1]. Surgically removed palatine tonsils provide a conventional accessible source to study the interplay between foreign pathogens, allergens and the host immune system. Our previous studies demonstrated that tonsils are organs where immune regulation takes 
place in which allergen-specific regulatory $\mathrm{T}$ cells can be generated by mechanisms depending on plasmacytoid dendritic cells $[2,3]$. The expression of $\mathrm{T}$ cell- and interferon specific genes in tonsils has been shown to be closely related to existing viral infections, age, and allergic illnesses $[4,5]$. However, data are scarce on the differences in tonsillar virus infections and immune responses between patients with tonsillar hypertrophy or recurrent tonsillitis [6-8].

Tonsils appear to provide a good in vivo model for investigating the mechanisms of inflammatory processes and infections in lymphoid organs [2-5]. Therefore, we studied whether virus detection and $\mathrm{T}$ cell and interferon gene expressions differed between the two main indications of surgery, tonsillar hypertrophy or recurrent tonsillitis.

\section{Methods}

\section{Patients}

Human tonsil samples used in this study were acquired from 200 consecutive tonsillectomy patients who underwent tonsillectomy in Satakunta Central Hospital, Pori, Finland between April 2008 and March 2009. The inclusion criteria were elective tonsillectomy according to clinical indication and written informed consent from the study patient and/or his/her guardian. The study protocol was approved by the ethics committee of Satakunta Central Hospital, Pori, Finland. Study was initiated only after obtaining written consent from the participant or his/her guardian.

\section{Study protocol and sample collection}

A standard questionnaire was used to obtain information on allergic diseases and respiratory symptoms within 30 days before the operation (Additional file 1: Table 1). Tonsillectomy was performed according to routine clinical procedure. Internal tonsillar tissue was immediately cut in 3-4 mm cubes, stored in RNAlater RNA stabilization reagent (Qiagen, Hilden, Germany), incubated at $+4{ }^{\circ} \mathrm{C}$ until next working day and finally stored at $-80{ }^{\circ} \mathrm{C}$ after removal of the non-absorbed reagent. For viral analyses, a part of the tonsils and a nasopharyngeal aspirate were stored in dry tubes at $-80{ }^{\circ} \mathrm{C}$ [4]. Nasopharyngeal aspirate samples were obtained during anaesthesia using a standardized procedure [4]. Serum total 25(OH)D measurement was done using an immunoassay (Abbott Architect, Chicago, USA) and bioavailable levels of $25(\mathrm{OH}) \mathrm{D}$ were estimated using additional serum measurements (D-binding protein and albumin) and published formulae.

\section{Definitions}

Tonsillar hypertrophy group was defined as patients who underwent tonsillectomy because of obstructive symptoms such as snoring, breathing difficulties or swallowing problems. There were no tonsillar infection problems in this group. Recurrent tonsillitis group was defined as patients who underwent tonsillectomy because of recurrently infected tonsils (viral or bacterial) during the past 6-12 months. Those operated because of acute infection or peritonsillar abscess were excluded.

\section{Analysis of viruses and cytokines}

In-house real-time PCR assays were used to detect human bocavirus-1, rhinovirus, enterovirus, and respiratory syncytial virus as described previously [4]. Seeplex RV12 ACE Detection (Seegene, Seoul, Korea) multiplex PCR assay was used for detection of adenovirus, coronaviruses (229E/NL63 and OC43/HKU1), influenza A and $B$ viruses, metapneumovirus, parainfluenza virus types $1-3$, respiratory syncytial virus group $A$ and $B$, and rhinovirus $[4,5]$. Virus diagnostics were carried out in the Department of Virology, University of Turku, Turku, Finland, and in the Department of Clinical Microbiology, Karolinska University Hospital, Stockholm, Sweden.

To isolate total RNA from palatine tonsils, tissues (previously stabilized in RNAlater) were homogenized in grinding tubes containing CK28 ceramic beads by using a Precellys 24 homogenizer (Bertin Technologies, Montigny le Bretonneux, France) two times at $6000 \mathrm{rpm}$ for $50 \mathrm{~s}$ [4]. Total RNA from cell samples was isolated using the RNeasy mini kit (Qiagen, Hilden, Germany). Reverse transcription was performed with the Revert Aid M-MuLV Reverse Transcriptase (Fermentas, St. LeonRot, Germany) using random hexamer primers according to the manufacturers protocol. Gene expressions of IFN$\alpha$, IFN- $\beta$, IFN- $\gamma$, IL-10, IL-13, IL-17, IL-28, IL-29, IL-37, TGF- $\beta$, FOXP3, GATA3, RORC2 and Tbet were analysed by quantitative real-time PCR using iTaq SYBR Green Supermix with ROX (Bio-Rad, Hercules, CA, USA) on a 7900HT Fast Real-Time PCR instrument (Applied Biosystems, Foster City, CA, USA). Housekeeping gene elongation factor $1 \alpha(E F 1 \alpha)$ was used for normalization. Data are shown as relative expressions, which show $2^{-(\Delta \mathrm{CT})}$ values multiplied by $10^{4}$, where $\Delta \mathrm{CT}$ corresponds to the difference between the $\mathrm{CT}$ value for the gene of interest and $\mathrm{EF} 1 \alpha$.

\section{Statistical analysis}

Continuous variables are described as medians and interquartile ranges, and were analysed using Mann-Whitney $\mathrm{U}$ test due to skewed distribution. Categorical variables 
are expressed as frequencies and percentages, and were analysed using Chi square test or Fisher exact test. Clinical, viral and immunological differences between study groups were analysed using unadjusted and multivariable linear regression analysis. The adjustments for immunologic analyses were chosen using backward stepwise multivariable models that initially included clinical factors and virus infections which significantly differed between the groups (age, self-reported pollen allergy, self-smoking, both adenotomy and tonsillectomy performed, respiratory symptoms one month prior to the operation and bioavailable $25(\mathrm{OH}) \mathrm{D}$ level). The final model was adjusted only for age. Before regression analyses, cytokine and transcription factor values were logtransformed because of positively skewed distributions. The mean difference was computed for log-transformed values: a recurrently infected group minus hypertrophic group. Statistical analysis was completed using JMP version 12.0.1 software (SAS Institute Inc. Cary, NC, USA). A two-sided $P<0.05$ was considered statistically significant.

\section{Results}

\section{Study population}

Originally, 200 patients participated in the study. Of them, 46 subjects did not have remaining tonsil and/ or nasopharyngeal samples for the current analysis, and 11 had no intratonsillar virology done in their samples. Another 54 subjects were excluded for having mixed indications of operation other than hypertrophy or tonsillitis (Fig. 1). Thus, 89 patients comprised the analytic cohort. Forty-seven (53\%) of them had tonsillar hypertrophy and $42(47 \%)$ had recurrent tonsillitis.

\section{Patient characteristics}

All operations were performed during afebrile period of chronic tonsil condition. Respiratory symptoms on the operation day were present equally in the hypertrophy group and the recurrent tonsillitis group (15 vs. $18 \%$, respectively; $P=0.72$ ). The median age of the patients was 8 years (range 2-46) and 20 years (range $7-60)$, respectively $(P<0.001)$ (Table 1$)$. In addition to being younger, patients in the hypertrophy group had more often adenotomy and tonsillectomy done, had

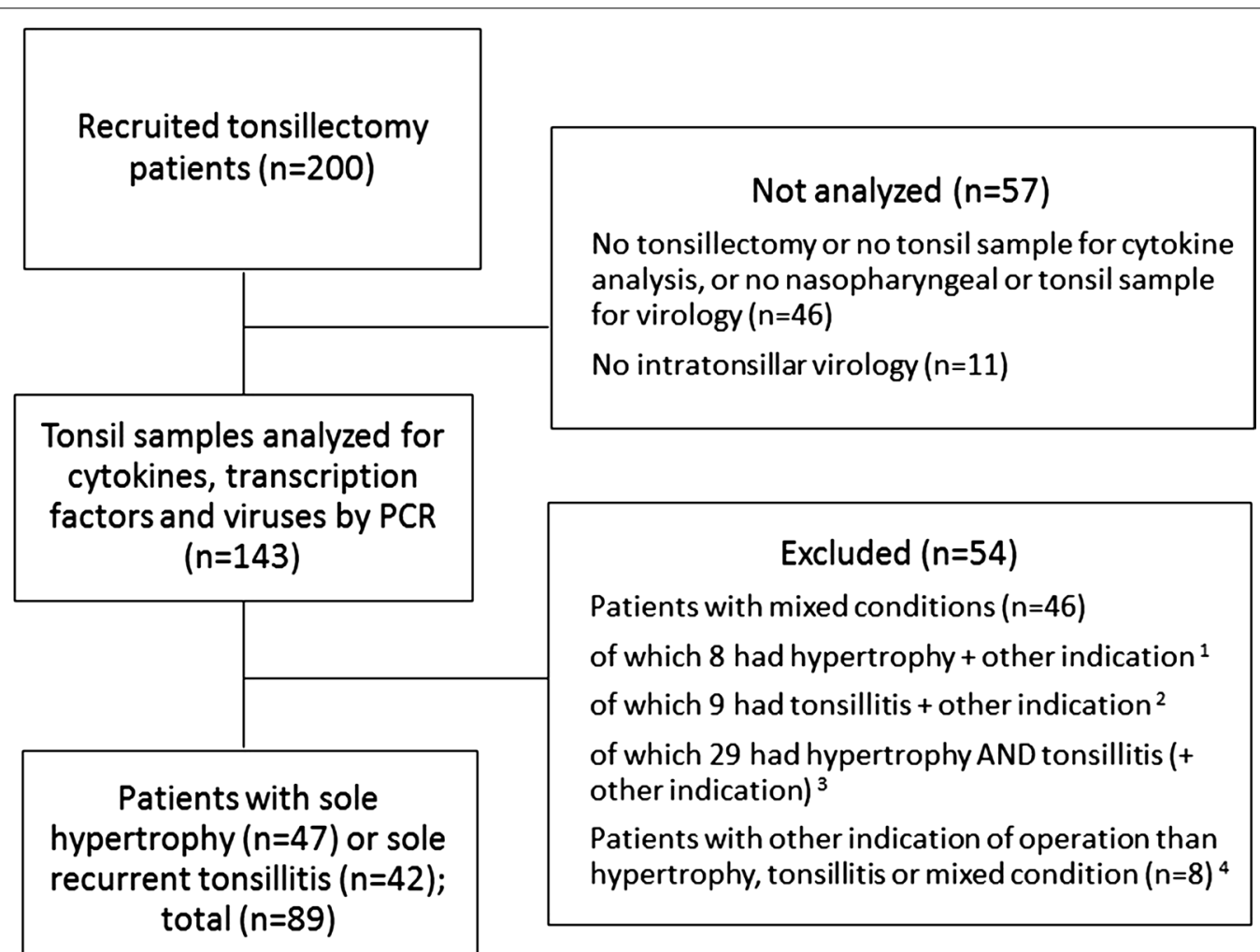

Fig. 1 Study flow chart. ${ }^{1} 8$ had hypertrophy and another indication (recurrent otitis media $n=4$; recurrent otitis media and fever $n=3$; recurrent fever $n=1$ ). ${ }^{2} 9$ had recurrent tonsillitis and another indication (recurrent fever $n=8$; recurrent otitis media $n=1$ ). ${ }^{3} 21$ had hypertrophy and tonsillitis; 8 had hypertrophy, tonsillitis, and another indication (recurrent fever, $n=5$; recurrent otitis media, recurrent fever $n=1$; recurrent otitis media $n=2$ ). ${ }^{4} 8$ had other indication of operation than hypertrophy or tonsillitis (chronic white patches in tonsils $n=2$; accumulation of food remnants, bad smelling breath, and feeling of beat in throat $n=1$; recurrent fever $n=1$; teeth braces $n=2$; throat abscess $n=1$; no clear cause $n=1$ ) 
Table 1 Patient characteristics

\begin{tabular}{|c|c|c|c|}
\hline Characteristics & $\begin{array}{l}\text { Tonsillar hypertrophy } \\
\mathrm{n}=47\end{array}$ & $\begin{array}{l}\text { Recurrent tonsillitis } \\
n=42\end{array}$ & $P$ value \\
\hline Age, years (range) & $8(2,46)$ & $20(7,60)$ & $<0.0001$ \\
\hline Male & $27(57 \%)$ & $23(55 \%)$ & 0.80 \\
\hline Tonsillectomy and adenotomy & $28(60 \%)$ & $5(12 \%)$ & $<0.0001$ \\
\hline Self-reported allergy & $20 / 43(47 \%)$ & $23 / 40(58 \%)$ & 0.32 \\
\hline Food & $6 / 43(14 \%)$ & $3 / 39(8 \%)$ & 0.38 \\
\hline Drug & $4 / 43(9 \%)$ & $4 / 39(10 \%)$ & 0.87 \\
\hline Seasonal, i.e. pollen & 0/43 (0\%) & $7 / 39(18 \%)$ & 0.004 \\
\hline Perennial, i.e. animal or house dust mite & $3 / 43(7 \%)$ & $2 / 39(5 \%)$ & 0.74 \\
\hline Other & $2 / 43(5 \%)$ & $2 / 39(5 \%)$ & 0.90 \\
\hline Multiple & $5 / 43(12 \%)$ & $4 / 39(10 \%)$ & 0.86 \\
\hline Physician-diagnosed atopic dermatitis & $11 / 44(25 \%)$ & $4 / 38(11 \%)$ & 0.09 \\
\hline Self-reported allergic rhinitis & $11 / 44(25 \%)$ & $11 / 39(28 \%)$ & 0.74 \\
\hline Physician-diagnosed asthma & $6 / 42(14 \%)$ & $6 / 39(15 \%)$ & 0.89 \\
\hline Self-smoking & $2 / 43(5 \%)$ & $14 / 40(35 \%)$ & 0.0005 \\
\hline Maternal smoking & $15 / 44(34 \%)$ & $13 / 41(32 \%)$ & 0.82 \\
\hline Paternal smoking & 16/41 (39\%) & 19/36 (53\%) & 0.23 \\
\hline Season of the surgery & & & 0.85 \\
\hline Winter (months 12-2) & $7(15 \%)$ & $4(10 \%)$ & \\
\hline Spring (months 3-5) & $14(30 \%)$ & $13(31 \%)$ & \\
\hline Summer (months 6-8) & $8(17 \%)$ & $5(12 \%)$ & \\
\hline Fall (months 9-11) & $18(38 \%)$ & $20(48 \%)$ & \\
\hline \multicolumn{4}{|l|}{ Respiratory symptoms } \\
\hline The operation day & $6 / 39(15 \%)$ & $7 / 38(18 \%)$ & 0.72 \\
\hline Within 2 weeks & $16 / 42(38 \%)$ & $12 / 37(32 \%)$ & 0.60 \\
\hline Within 4 weeks & 23/42 (55\%) & $18 / 37(48 \%)$ & 0.59 \\
\hline \multicolumn{4}{|l|}{ One month prior the operation } \\
\hline Throat pain & $8 / 39(21 \%)$ & $14 / 35(40 \%)$ & 0.0005 \\
\hline Rhinitis & 23/39 (59\%) & $6 / 35(17 \%)$ & 0.0002 \\
\hline Cough & 15/39 (38\%) & $5 / 36(14 \%)$ & 0.02 \\
\hline Acute otitis media & $2 / 39(5 \%)$ & $0 / 35(0 \%)$ & 0.17 \\
\hline Wheezing & $2 / 39(5 \%)$ & $0 / 35(0 \%)$ & 0.17 \\
\hline \multicolumn{4}{|l|}{ 25(OH)D level } \\
\hline Total (nmol/l) & $56.2(41.7,66.9)$ & $45.7(34.4,72.3)$ & 0.08 \\
\hline Free $(\mathrm{pg} / \mathrm{ml})$ & $6.4(4.9,8.1)$ & $5.0(3.3,8.8)$ & 0.14 \\
\hline Bioavailable (ng/ml) & $2.2(1.7,2.9)$ & $1.6(1.1,2.7)$ & 0.01 \\
\hline
\end{tabular}

Values are shown as median (interquartile range, except age) or number of subjects (\%). Data were analysed by Mann-Whitney U test, Chi square test, or Fisher's Exact test

Significant values are shown in italic

less self-reported pollen allergy, smoked less, and had less throat pain, but had more often rhinitis and cough 1 month prior the operation and higher bioavailable $25(\mathrm{OH}) \mathrm{D}$ level than patients in the recurrent tonsillitis group (all $P<0.01$ ) (Table 1 ). Otherwise no significant differences were found between the two groups.

Viruses detected in nasopharyngeal aspirates and tonsils Significantly more patients in the hypertrophy group, compared to the recurrent tonsillitis group, had a virus in their nasopharyngeal aspirates (79 vs. $38 \%$, respectively; $P<0.001)$. In addition, patients in the hypertrophy group had more often adenovirus, bocavirus-1, coronavirus or rhinovirus in nasopharyngeal aspirate (all $P<0.05)$ (Table 2). However, intratonsillar virus detection didn't show statistically significant differences, except for bocavirus-1 which was detected in tonsils in $15 \%$ of patients with hypertrophy and only $2 \%$ of patients in recurrent tonsillitis group (Table 2). Patients in the hypertrophy group were more often positive for one 
Table 2 Nasopharyngeal and intratonsillar virus detection

\begin{tabular}{|c|c|c|c|c|c|c|}
\hline \multirow[t]{2}{*}{ Virus } & \multicolumn{2}{|l|}{ Nasopharynx } & \multirow[t]{2}{*}{$P$ value } & \multicolumn{2}{|l|}{ Tonsil } & \multirow[t]{2}{*}{$P$ value } \\
\hline & $\begin{array}{l}\text { Tonsillar hypertrophy } \\
n=47\end{array}$ & $\begin{array}{l}\text { Recurrent tonsillitis } \\
n=42\end{array}$ & & $\begin{array}{l}\text { Tonsillar hypertrophy } \\
n=47\end{array}$ & $\begin{array}{l}\text { Recurrent tonsillitis } \\
n=42\end{array}$ & \\
\hline Adenovirus & $9(19 \%)$ & $2(5 \%)$ & 0.03 & $7(15 \%)$ & $2(5 \%)$ & 0.10 \\
\hline Bocavirus-1 & $12(26 \%)$ & $2(5 \%)$ & 0.005 & $7(15 \%)$ & $1(2 \%)$ & 0.03 \\
\hline Coronavirus & $3(6 \%)$ & $0(0 \%)$ & 0.048 & $0(0 \%)$ & $0(0 \%)$ & - \\
\hline Enteroviruses & $4(9 \%)$ & $4(10 \%)$ & 0.87 & $6(13 \%)$ & $4(10 \%)$ & 0.63 \\
\hline Influenza A or B virus & $1(2 \%)$ & $0(0 \%)$ & 0.26 & $0(0 \%)$ & $0(0 \%)$ & - \\
\hline Metapneumovirus & $0(0 \%)$ & $1(2 \%)$ & 0.29 & $1(2 \%)$ & $0(0 \%)$ & 0.26 \\
\hline Parainfluenza virus types 1-4 & $1(2 \%)$ & $1(2 \%)$ & 0.94 & $4(9 \%)$ & $1(2 \%)$ & 0.19 \\
\hline Respiratory syncytial virus & $1(2 \%)$ & $0(0 \%)$ & 0.26 & $2(4 \%)$ & $0(0 \%)$ & 0.11 \\
\hline Rhinovirus species A, B or C & $27(57 \%)$ & $14(33 \%)$ & 0.02 & $2(4 \%)$ & $2(5 \%)$ & 0.91 \\
\hline Number of positive viruses & $37(79 \%)$ & $16(38 \%)$ & $<0.0001$ & $17(36 \%)$ & $8(19 \%)$ & 0.07 \\
\hline Positive for 1 virus & $23(49 \%)$ & $10(24 \%)$ & 0.01 & $9(19 \%)$ & $7(17 \%)$ & 0.76 \\
\hline Positive for 2 viruses & $8(17 \%)$ & $4(10 \%)$ & 0.30 & $5(11 \%)$ & $0(0 \%)$ & 0.01 \\
\hline Positive for 3 viruses & $5(11 \%)$ & $2(5 \%)$ & 0.30 & $2(4 \%)$ & $1(2 \%)$ & 0.62 \\
\hline Positive for 4 viruses & $1(2 \%)$ & $0(0 \%)$ & 0.26 & $1(2 \%)$ & $0(0 \%)$ & 0.26 \\
\hline Positive for $\geq 1$ viruses & 37 (79\%) & $16(38 \%)$ & & $17(36 \%)$ & $8(19 \%)$ & \\
\hline Positive for $\geq 2$ viruses & $14(30 \%)$ & $6(14 \%)$ & & $8(17 \%)$ & $1(2 \%)$ & \\
\hline Positive for $\geq 3$ viruses & $6(13 \%)$ & $2(5 \%)$ & & $3(7 \%)$ & $1(2 \%)$ & \\
\hline Positive for $\geq 4$ viruses & $1(2 \%)$ & 0 & & $1(2 \%)$ & 0 & \\
\hline
\end{tabular}

Values are shown as number of subjects (\%). Data were analysed by Chi square test, or Fisher's Exact test

Significant values are shown in italic

virus in their nasopharyngeal aspirates (49 vs. 24\%) or two viruses in their tonsils ( 11 vs. $0 \%$, respectively) (both $P<0.05$ ) (Table 2).

\section{Cytokine and transcription factor expression profiles in tonsils}

In unadjusted analysis, patients in the hypertrophy group had stronger tonsillar expression of Tbet $(P=0.03)$ and IL-37 $(P=0.001)$ than patients in the recurrent tonsillitis group (Tables 3,4$)$. In the multivariable regression analysis, only age remained as a significant co-factor (Table 4). After adjustment for age, the expressions of only IL-37 was independently associated with tonsillar hypertrophy group $(P<0.05$, Fig. 2$)$. No other differences in cytokine or transcription factor expression were found between the groups.

\section{Discussion}

This study shows differences in virus detections and $\mathrm{T}$ cell and interferon gene expressions in patients undergoing tonsillectomy due to tonsillar hypertrophy or recurrent tonsillitis. Patients with tonsillar hypertrophy were typically younger, and had more viral findings, but only bocavirus-1 was more often found in tonsils when compared to patients with recurrent tonsillitis. Respectively, they also had less self-reported pollen allergy, but no differences were found in food allergies between the
Table 3 Intratonsillar cytokine and transcription factor expression in hypertrophic tonsils and recurrent tonsillitis

\begin{tabular}{|c|c|c|}
\hline $\begin{array}{l}\text { Cytokine } \\
\text { or transcription factor }\end{array}$ & $\begin{array}{l}\text { Tonsillar hypertrophy } \\
\mathrm{n}=47 \\
\text { Median (IQR) }\end{array}$ & $\begin{array}{l}\text { Recurrent tonsillitis } \\
\mathrm{n}=42 \\
\text { Median (IQR) }\end{array}$ \\
\hline \multicolumn{3}{|l|}{ T-helper 1} \\
\hline $\mid F N-\gamma$ & $58(37,90)$ & $76(32,117)$ \\
\hline Tbet & $54(31,83)$ & $34(22,60)$ \\
\hline \multicolumn{3}{|l|}{ T-helper $_{2}$} \\
\hline IL-13 & $1.2(0.03,3.7)$ & $0.45(0.02,2.2)$ \\
\hline GATA3 & $27(16,36)$ & $18(12,39)$ \\
\hline \multicolumn{3}{|l|}{ T-helper 17} \\
\hline $\mathrm{IL}-17$ & $10(5.6,19)$ & $7.3(4.1,13)$ \\
\hline RORC2 & $15(7.2,31)$ & $20(10,28)$ \\
\hline \multicolumn{3}{|l|}{ T-regulatory } \\
\hline IL-10 & $49(24,74)$ & $35(21,64)$ \\
\hline IL-37 & $0.26(0.15,0.37)$ & $0.14(0.10,0.24)$ \\
\hline FOXP3 & $46(20,87)$ & $48(24,80)$ \\
\hline TGF- $\beta$ & $163(105,232)$ & $171(120,225)$ \\
\hline \multicolumn{3}{|l|}{ Type I/III interferons } \\
\hline IFN-a & $15(0.59,62)$ & $9.7(0.27,56)$ \\
\hline IFN- $\beta$ & $24(2.7,101)$ & $22(2.1,103)$ \\
\hline $\mathrm{IL}-28$ & $31(3.1,88)$ & $12(1.4,75)$ \\
\hline $\mathrm{IL}-29$ & $11(2.3,34)$ & $3.7(1.3,26)$ \\
\hline
\end{tabular}

Values are arbitrary units $\times 10^{4}$ relative to $\mathrm{EF} 1 \mathrm{a}$

$\mathrm{IQR}$, interquartile range; IFN, interferon; Tbet, T-box transcription factor; IL, interleukin; GATA3, GATA-binding factor 3; RORC, RAR-related orphan receptor C. FOXP, forkhead box protein; TGF, tumour growth factor 
Table 4 Differences in cytokine and transcription factor expression between hypertrophic tonsils and recurrent tonsillitis

\begin{tabular}{|c|c|c|c|c|}
\hline \multirow[t]{3}{*}{ Cytokine or transcription factor } & \multicolumn{4}{|c|}{ Mean differences recurrently infected minus hypertrophic group } \\
\hline & \multicolumn{2}{|c|}{ Univariate } & \multicolumn{2}{|l|}{ Multivariate } \\
\hline & n & Difference of means $(95 \% \mathrm{Cl})$ & Adjusted difference of means $(95 \% \mathrm{Cl})$ & Adjustments \\
\hline \multicolumn{5}{|l|}{ T-helper $_{1}$} \\
\hline $\mathrm{IFN}-\mathrm{Y}$ & 88 & $\begin{array}{l}0.061(-0.32,0.44) \\
P=0.75\end{array}$ & - & - \\
\hline Tbet & 89 & $\begin{array}{l}-0.40(-0.76,-0.034) \\
P=0.03\end{array}$ & $\begin{array}{l}-0.21(-0.61,0.18) \\
P=0.29\end{array}$ & Age \\
\hline \multicolumn{5}{|l|}{ T-helper $_{2}$} \\
\hline IL-13 & 89 & $\begin{array}{l}-0.74(-1.8,0.36) \\
P=0.18\end{array}$ & - & - \\
\hline GATA3 & 89 & $\begin{array}{l}-0.12(-0.42,0.18) \\
P=0.43\end{array}$ & - & - \\
\hline \multicolumn{5}{|l|}{ T-helper ${ }_{17}$} \\
\hline $\mathrm{IL}-17$ & 89 & $\begin{array}{l}-0.35(-0.80,0.096) \\
P=0.12\end{array}$ & $\begin{array}{l}-0.087(-0.57,0.40) \\
P=0.72\end{array}$ & Age \\
\hline RORC2 & 89 & $\begin{array}{l}0.014(-0.35,0.38) \\
P=0.94\end{array}$ & - & - \\
\hline \multicolumn{5}{|l|}{ T-regulatory } \\
\hline$\| \mathrm{L}-10$ & 89 & $\begin{array}{l}-0.26(-0.61,0.0871) \\
P=0.14\end{array}$ & $\begin{array}{l}-0.0070(-0.38,0.36) \\
P=0.97\end{array}$ & Age \\
\hline IL-37 & 87 & $\begin{array}{l}-0.48(-0.77,-0.19) \\
P=0.001\end{array}$ & $\begin{array}{l}-0.31(-0.63,-0.0021) \\
P=0.049\end{array}$ & Age \\
\hline FOXP3 & 89 & $\begin{array}{l}0.091(-0.31,0.49) \\
P=0.65\end{array}$ & - & - \\
\hline TGF- $\beta$ & 89 & $\begin{array}{l}-0.0077(-0.32,0.30) \\
P=0.96\end{array}$ & - & - \\
\hline \multicolumn{5}{|l|}{ Type I/III interferons } \\
\hline IFN-a & 87 & $\begin{array}{l}-0.41(-1.5,0.7) \\
P=0.47\end{array}$ & - & - \\
\hline IFN- $\beta$ & 88 & $\begin{array}{l}-0.21(-1.0,0.61) \\
P=0.62\end{array}$ & - & - \\
\hline IL-28 & 89 & $\begin{array}{l}-0.64(-1.5,0.2) \\
P=0.13\end{array}$ & - & - \\
\hline IL-29 & 87 & $\begin{array}{l}-0.57(-1.5,0.31) \\
P=0.15\end{array}$ & - & - \\
\hline
\end{tabular}

Data are expressed as mean differences as a recurrently infected group minus hypertrophic group. The data were analysed using backward stepwise linear regression analysis after logarithmic transformation. Only significant co-factors were used as adjustments in the final model

$\mathrm{Cl}$, confidence interval; IFN, interferon; Tbet, T-box transcription factor; IL, interleukin; GATA3, GATA-binding factor 3; RORC, RAR-related orphan receptor C; FOXP, forkhead box protein; TGF, tumour growth factor

Significant values are shown in italic

groups. After age-adjusted analysis, tonsillar hypertrophy was associated with higher tonsillar mRNA expressions of IL-37. Other than age, no other significant co-factors were found.

IL-37 (formerly IL-1 family member 7) is a fundamental inhibitor of innate immunity $[9,10]$. It has been shown to be expressed in macrophages, monocytes, plasma and epithelial cells [11]. After ligand activation, IL-37 inhibits inflammatory cytokines (especially IL- $1 \beta$, but also IL-6, IL-7, IFN- $\gamma$, and TNF- $\alpha$ ) and augments the level of antiinflammatory IL-10 and T regulatory cells [11]. We have previously shown that the expression of IL-37 is closely and positively associated with other "immune activation/regulatory" cytokines (IL-10, IL-17, IL-37, TGF- $\beta$, FOXP3, GATA3, RORC2, Tbet) in tonsils [2]. The current analysis adds that tonsillar expression of anti-inflammatory cytokine IL-37 is also independently and positively associated with tonsillar hypertrophy.

Interferons (IFN- $\alpha$, IFN- $\beta$, IFN- $\gamma$, IL-28, IL-29) are cytokines with antiviral activity and their expression is induced by viral infection. IL-28 and IL-29 are members of IFN- $\lambda$ family $[12,13]$. They are produced by dendritic 


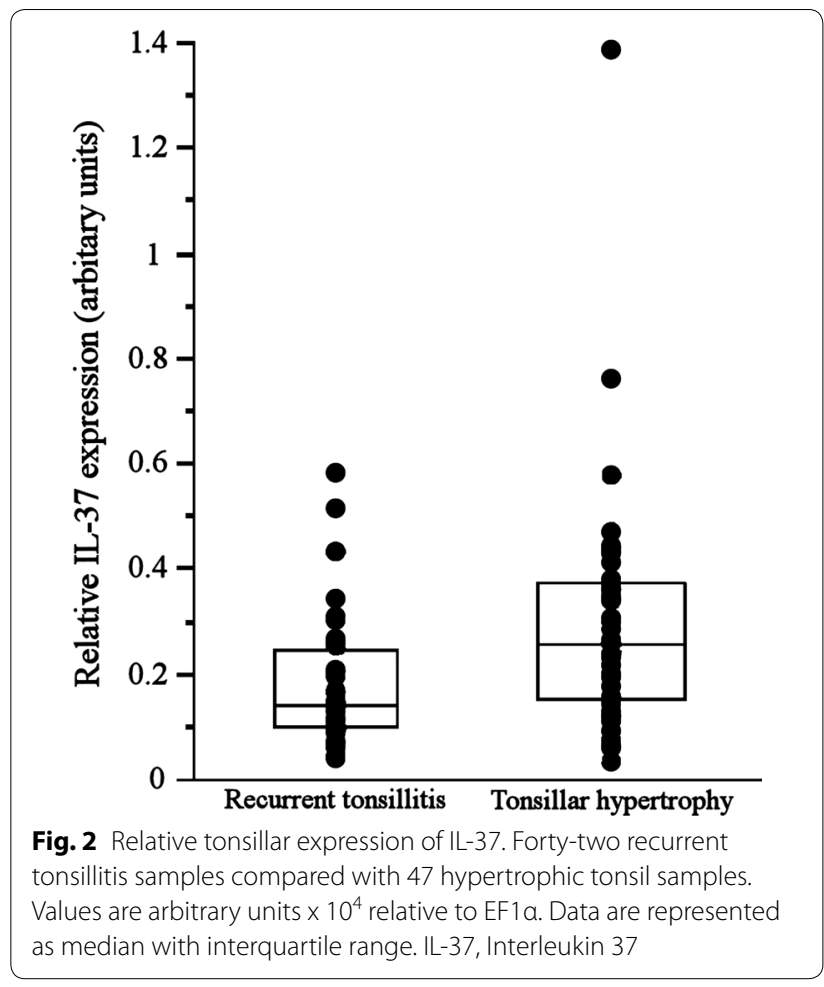

cells and macrophages following viral infection or activation with bacterial components [12-14]. We expected to see differences in IFN expression (lower responses in recurrent tonsillitis than in tonsillar hypertophy group), since they have antiviral properties and they up-regulate the expression of MHC Class II molecules on cells which increases the immune system's ability to recognize viruses $[14,15]$. However, we did not observe these differences. We speculate that tonsillar hypertophy may be a consequence of chronic inflammation in tonsils and the same interferon pathways are equally activated in both conditions. We have previously found strong intragroup correlations of tonsillar IFN expression(IFN- $\alpha$, IFN- $\beta$, IFN- $\gamma$, IL-28) [2].

Age was the main clinical characteristic differentiating the tonsillectomy indication groups. In agreement with previous findings [16], we found that obstruction due to the hypertrophy is more common with younger children where as adults have more recurrent tonsillitis. The age difference between the groups also explains the differences in smoking and in additional adenotomy performed. Interestingly, Reis and colleagues found no difference between the age distribution of hypertrophy and tonsillitis patients, but the narrow age range of their subjects (ages 2-11 years) may explain the lack of difference [17].

Virus was found in the nasopharynx of $79 \%$ of patients with tonsillar hypertrophy group and 38\% in recurrent tonsillitis group. Most often detected viruses were adenovirus, bocavirus-1, coronavirus and rhinovirus. However, intratonsillar virus detection was low and did not show any statistically significant differences except for bocavirus-1. The results of nasopharyngeal and intratonsillar virus detection vs tonsillar cytokine responses are discussed in detail in our previous report [2].

Small differences in cytokine expression may partly be explained by differences concerning tonsillar germinal centers. The mean follicular area has been found to be larger, and the number of germinal centers higher, in the hypertrophy group compared to the recurrent tonsillitis [17-19]. In our study, the samples were taken from inside of the tonsils to minimize the margin of error and the possibility to misinterpreted differences between the groups. Seasonal changes, e.g. pollen and influenza seasons, may affect the expression of peripheral $\mathrm{T}$ cells [20], but we found no differences in tonsillar expression of cytokines between the seasons of the surgery. Also, respiratory viruses are continuously detected in children with chronic tonsillitis throughout the year [21-23]. Circulating serum 25(OH)D level has been shown to been positively associated with IL-37 level [3], but here it did not confound the results.

A limitation of the current study is that we did not investigate bacterial colonization of the tonsils in these patients due to fact that the operation was done during an afebrile period of their chronic tonsil condition. The downstream signaling of IL-37 is a complex process and to show functionality of IL-37 by downstream mediators was not in the scope of this study. In addition to forming cell-surface receptor complexes, IL-37 translocates to the nucleus where it binds to nuclear DNA and participate in transcription. [24, 25] IL-37 is regarded as a "dual function" cytokine, similar to IL- $1 \alpha$ and IL-33.

\section{Conclusions}

In summary, this study provides new insights about $\mathrm{T}$ cell research in lymphoid tissue from the clinical aspect of the surgical indication for tonsillectomy. We found tonsils as a good in vivo model for investigating the mechanisms of inflammatory processes and infections in lymphoid organs. Our data suggest that T-cell and interferon gene expressions appear to relatively stable over the two main indications of tonsillectomy, tonsillar hypertrophy and recurrent tonsillitis. However, anti-inflammatory immune responses, namely IL-37, might be slightly stronger in patients with tonsillar hypertrophy than with patients with recurrent tonsillitis.

\section{Additional file}

Additional file 1. Health questionnaire. 


\section{Authors' contributions}

The study protocol and manuscript were written by the investigators. Tonsil samples and clinical data were collected by TP, MS and LI. Viral analyses were performed by MW, TVu and TA Cytokine analyses were conducted by OP, RT, $\mathrm{BR}, \mathrm{AA}$ and supervised by MA and CAA. CAC organized the vitamin D analyses. Data were analyzed by EM, VE, MS and TJ and by statistician TVa. All authors read and approved the final manuscript.

\begin{abstract}
Author details
${ }^{1}$ Department of Otorhinolaryngology, Turku University Hospital and Turku University, Turku, Finland. ${ }^{2}$ Department of Paediatrics and Adolescent Medicine, Turku University Hospital and Turku University, P.O. Box 52, 20520 Turku, Finland. ${ }^{3}$ Swiss Institute of Allergy and Asthma Research, University of Zürich Davos, Switzerland. ${ }^{4}$ Christine Kühne-Center for Allergy Research and Education, Davos, Switzerland. ${ }^{5}$ Department of Biochemistry and Molecular Biology, School of Chemistry, Complutense University of Madrid, Madrid, Spain. ${ }^{6}$ Department of Clinical Virology, Turku University Hospital, Turku, Finland. ${ }^{7}$ Department of Virology, University of Turku, Turku, Finland. ${ }^{8}$ Department of Otorhinolaryngology, Satakunta Central Hospital, Pori, Finland. ${ }^{9}$ Department of Biostatistics, University of Turku and Turku University Hospital, Turku, Finland. ${ }^{10}$ Department of Clinical Microbiology, Karolinska University Hospital, Stockholm, Sweden. ${ }^{11}$ Department of Emergency Medicine, Massachusetts General Hospital, Harvard Medical School, Boston, USA. ${ }^{12}$ Division of Rheumatology, Allergy and Immunology, Department of Medicine, Massachusetts General Hospital, Harvard Medical School, Boston, USA.
\end{abstract}

\section{Competing interests}

The authors declare that they have no competing interests.

\section{Ethics approval and consent to participate}

The study protocol was approved by the ethics committee of Satakunta Central Hospital, Pori, Finland. Study was initiated only after obtaining written consent from the participant or his/her guardian.

\section{Funding}

TJ and his laboratory are supported by the Academy of Finland (Grants 114034 and 132595), the Finnish Medical Foundation, the Sigrid Juselius Foundation, and the Foundation for Pediatric Research. EM and MS are supported by the Foundation for Pediatric Research. VE is supported by Tampere Tuberculosis Foundation. OP is a Ramon y Cajal Scholar funded by MINECO and the European Social Fund. MA's laboratory is sponsored by EU 7th Framework Program PREDICTA: Post-Infectious Immune Reprogramming and Its Association with Persistence and Chronicity of Respiratory Allergic Diseases (No. 260895). Laboratory of CAA is supported by the Swiss National Science Foundation Grant 32-132899 and Christine Kühne-Center for Allergy Research and Education. The granting agencies covered all costs and played no role in study design, data analysis, or manuscript preparation.

\section{Publisher's Note}

Springer Nature remains neutral with regard to jurisdictional claims in published maps and institutional affiliations.

Received: 9 December 2017 Accepted: 16 April 2018 Published online: 22 May 2018

\section{References}

1. Ogra PL. Mucosal immune response in the ear, nose and throat. Pediatr Infect Dis J. 2000;19(5 Suppl):S4-8.

2. Palomares $\mathrm{O}$, Rückert B, Jartti T, Kücüksezer UC, Puhakka T, Gomez E, et al. Induction and maintenance of allergen-specific FOXP3+ Treg cells in human tonsils as potential first-line organs of oral tolerance. J Allergy Clin Immunol. 2012;129(2):510-20.

3. Kücüksezer UC, Palomares O, Rückert B, Jartti T, Puhakka T, Nandy A, et al. Triggering of specific Toll-like receptors and proinflammatory cytokines breaks allergen-specific T-cell tolerance in human tonsils and peripheral blood. J Allergy Clin Immunol. 2013;131(3):875-85.

4. Jartti T, Palomares O, Waris M, Tastan O, Nieminen R, Puhakka T, et al. Distinct regulation of tonsillar immune response in virus infection. Allergy. 2014;69(5):658-67.
5. Elenius $V$, Palomares $\mathrm{O}$, Waris $\mathrm{M}$, Turunen $\mathrm{R}$, Puhakka T, Rückert $\mathrm{B}$, et al. The relationship of serum vitamins $A, D, E$ and $L L-37$ levels with allergic status, tonsillar virus detection and immune response. PLOS ONE. 2017;12(2):e0172350.

6. Andersson J, Abrams J, Björk L, Funa K, Litton M, Agren K, et al. Concomitant in vivo production of 19 different cytokines in human tonsils. Immunology. 1994;83(1):16-24.

7. Kim J, Bhattacharjee R, Dayyat E, Snow AB, Kheirandish-Gozal L, Goldman $J$, et al. Increased cellular proliferation and inflammatory cytokines in tonsils derived from children with obstructive sleep apnea. Pediatr Res. 2009;66(4):423-8.

8. Woon HG, Braun A, Li J, Smith C, Edwards J, Sierro F, et al. Compartmentalization of total and virus-specific tissue-resident memory $C^{8+} \mathrm{T}$ cells in human lymphoid organs. PLoS Pathog. 2016;12(8):e1005799.

9. Nold MF, Nold-Petry CA, Zepp JA, Palmer BE, Bufler P, Dinarello CA IL-37 is a fundamental inhibitor of innate immunity. Nat Immunol. 2010;11(11):1014-22

10. Banchereau J, Pascual V, O'Garra A. From IL-2 to IL-37: the expanding spectrum of anti-inflammatory cytokines. Nat Immunol. 2012:13(10):925-31.

11. Conti P, Carinci F, Lessiani G, Spinas E, Kritas SK, Ronconi G, et al. Potential therapeutic use of IL-37: a key suppressor of innate immunity and allergic immune responses mediated by mast cells. Immunol Res. 2017:65(5):982-6.

12. Kelm NE, Zhu Z, Ding VA, Xiao H, Wakefield MR, Bai Q, et al. The role of IL-29 in immunity and cancer. Crit Rev Oncol Hematol. 2016;106:91-8.

13. Witte K, Witte E, Sabat R, Wolk K. IL-28A, IL-28B, and IL-29: promising cytokines with type I interferon-like properties. Cytokine Growth Factor Rev. 2010;21(4):237-51.

14. Akdis M, Burgler S, Crameri R, Eiwegger T, Fujita H, Gomez E, et al. Interleukins, from 1 to 37, and interferon-y: receptors, functions, and roles in diseases. J Allergy Clin Immunol. 2011;127(3):701-21.

15. Commins S, Steinke JW, Borish L. The extended IL-10 superfamily: IL-10, IL-19, IL-20, IL-22, IL-24, IL-26, IL-28, and IL-29. J Allergy Clin Immunol. 2008:121(5):1108-11.

16. Rosenmann E, Rabinowitz R, Schlesinger M. Lymphocyte subsets in human tonsils: the effect of age and infection. Pediatr Allergy Immunol. 1998:9(3):161-7.

17. Reis LG, Almeida EC, da Silva JC, GeA Pereira, VeF Barbosa, Etchebehere RM. Tonsillar hyperplasia and recurrent tonsillitis: clinical-histological correlation. Braz J Otorhinolaryngol. 2013;79(5):603-8.

18. Zhang PC, Pang YT, Loh KS, Wang DY. Comparison of histology between recurrent tonsillitis and tonsillar hypertrophy. Clin Otolaryngol Allied Sci. 2003;28(3):235-9.

19. Agren K, Andersson U, Litton M, Funa K, Nordlander B, Andersson J. The production of immunoregulatory cytokines is localized to the extrafollicular area of human tonsils. Acta Otolaryngol. 1996;1 16(3):477-85.

20. Jartti T, Burmeister KA, Seroogy CM, Jennens-Clough ML, Tisler CJ, Salazar $\mathrm{LP}$, et al. Association between $\mathrm{CD}^{4+} \mathrm{CD} 25$ (high) T cells and atopy in children. J Allergy Clin Immunol. 2007;120(1):177-83.

21. Proença-Módena JL, Buzatto GP, Paula FE, Saturno TH, Delcaro LS, Prates MC, et al. Respiratory viruses are continuously detected in children with chronic tonsillitis throughout the year. Int J Pediatr Otorhinolaryngol. 2014;78(10):1655-61.

22. Günel C, Kırdar S, Ömürlü İ, A $\breve{g}$ daş F. Detection of the Epstein-Barr virus, human bocavirus and novel $\mathrm{Kl}$ and $\mathrm{KU}$ polyomaviruses in adenotonsillar tissues. Int J Pediatr Otorhinolaryngol. 2015;79(3):423-7.

23. Comar M, Grasso D, dal Molin G, Zocconi E, Campello C. HHV-6 infection of tonsils and adenoids in children with hypertrophy and upper airway recurrent infections. Int J Pediatr Otorhinolaryngol. 2010;74(1):47-9.

24. Sharma S, Kulk N, Nold MF, Gräf R, Kim SH, Reinhardt D, et al. The IL-1 family member $7 \mathrm{~b}$ translocates to the nucleus and down-regulates proinflammatory cytokines. J Immunol. 2008;180(8):5477-82.

25. Bulau AM, Nold MF, Li S, Nold-Petry CA, Fink M, Mansell A, et al. Role of caspase-1 in nuclear translocation of IL-37, release of the cytokine, and IL-37 inhibition of innate immune responses. Proc Natl Acad Sci USA. 2014;111(7):2650-5. 